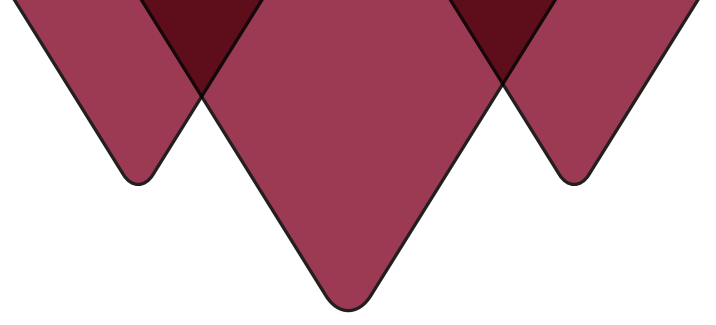

\title{
Material Entanglement and Technology Fetishism in Academic Libraries
}

\author{
Lisa Levesque \\ Ryerson University
}

ABSTRACT

This article explores technology fetishism in academic libraries as an irrational form of worship. Academic libraries participate in networks of prestige through their investments in technology and its fetishistic rhetoric. To counter the myth of technology as a neutral good, this article draws on contemporary fetishism theory and specifically the work of Bruno Latour to trace how technology is entangled with social relations and upholds hegemonic power. All technology is laden with human thought, feeling, and intent. However, Modern fetishes are dispersed into culture and obscure these entanglements, hiding materiality and obscuring the visibility oflabour. This article considers library technology through the lens offetishism, specifically considering the ways in which discovery layers shape research. Confronting fetishism enables academic library workers to reimagine more human-centered approaches to technology and to bring to light embedded whiteness and sexism in library practices. There is an urgent need to reconfigure our relationships with technology given its entanglement with research and the unexamined power that fetishism holds.

Keywords: discovery $\cdot$ fetishism $\cdot$ gender $\cdot$ invisibility $\cdot$ labour $\cdot$ materiality · power . search $\cdot$ technology $\cdot$ whiteness

\section{RÉSUMÉ}

Cet article explore le fétichisme de la technologie dans les bibliothèques universitaires comme une forme irrationnelle de culte. Les bibliothèques universitaires participent à des réseaux de prestige et de pouvoir par leurs investissements dans la technologie et sa rhétorique fétichiste. La technologie est vénérée comme étant objective parce qu'on l'imagine éloignée de l'humanité. Pour contrer le mythe de la technologie en tant que bien neutre, cet article s'appuie sur la théorie du fétichisme contemporain et plus particulièrement sur le travail de Bruno Latour pour démontrer comment la technologie est enchevêtrée avec les relations sociales et soutient le pouvoir hégémonique. Toute technologie est chargée de pensées, d'émotions et d'intentions humaines. Cependant, les fétiches modernes sont dispersés dans la culture et obscurcissent ces enchevêtrements, cachant la matérialité et rendant le travail des bibliothèques invisible. Ces questions sont étudiées en profondeur et les découvertes sont analysées pour démontrer comment la recherche est profondément façonnée par les outils qu'elle utilise. La lutte contre le fétichisme permet aux 
bibliothèques universitaires de réimaginer des approches technologiques plus centrées sur l'humain et de mettre en lumière la blanchité et le sexisme qui en font partie intégrante. Le besoin de reconfigurer nos relations avec la technologie est urgent étant donné son enchevêtrement avec la recherche et le pouvoir non étudié du fétichisme.

Mots-clés : blanchité découverte fétichisme genre invisibilité matérialité pouvoir recherche $\cdot$ technologie $\cdot$ travail

T

HE term "fetish" is used to describe an object imbued with magical qualities. This concept contains seeming contradictions: the inanimate lives, the ordinary hides the supernatural. Fetishes are imagined to be outdated, like the carved idols of former African colonies. However, the idea that fetishes are pre-Modern or primitive is a biased and false narrative. Modern fetishes exist but are unseen because they are distributed into culture, particularly in the contemporary worship of technology as benevolent, neutral, and a source of simple answers. This article draws on contemporary fetishism theory, particularly the work of Bruno Latour, to contradict the separation of human and non-human that lies at the heart of the Modern fetish. Its goal is to knit together library and information science scholarship that focuses on technology to expose the Modern fetish, and how it embeds and enacts hegemonic norms in academic library practices. To do this, I will first establish context by exploring the history of the fetish, explaining Latour's critique, and then summarize the relevant Library and Information Science literature. Then, I will explore how academic libraries are entangled with fetish objects in networks of higher education prestige and describe discovery layers as an example of technology fetishism. Critiquing technology forces us to confront problems of visibility that hide embedded racism and sexism, including hidden labour, black boxes that feign neutrality, and forgotten materiality. Finally, I will offer alternatives to technology fetishism by arguing that it is only by seeing technology clearly—tracing its networks, exposing its material nature, and identifying how power works through it-that academic libraries can reconfigure their relationships with technology to better serve the needs of humans in libraries, specifically members of marginalized groups.

\section{A Brief History of Fetishism}

In order to contextualize the contemporary Latourian critique that this paper will draw on, a very brief history of fetishism is required. The concept of fetishism as we know it today primarily has its origins in three dogmas: Christianity, psychoanalysis, and Marxism (Böhme 20I4, I3). Christian Portuguese colonists first used the term 
to describe African idolatry based on practices they observed in the country now known as Guinea. They claimed idol worship was irrational because worshippers venerated objects of their own creation (Latour 2010, 3). During the Enlightenment, the understanding of fetishism was extended beyond Africa to a general practice of Indigenous peoples in colonized lands across the globe, who treated objects with veneration, fear, or respect for their ritual powers. Western ethnologists, or anthropologists focusing on cultural comparisons, played an important role in collecting evidence of fetishistic practices that could be used to other those societies, or vilify as them as intrinsically different. Philosophers of the time, namely David Hume and Charles de Brosses, depicted fetishism as "primitive," a practice superseded by Modernity and Christianity (Böhme 20I4, I57).

In the late Igth and early 2oth centuries, fetishism began to be used in psychoanalysis to describe a sexual practice. Specifically, sexual fetishes displace desire from the human body and ascribe it to an object, such as a fur coat (Freud

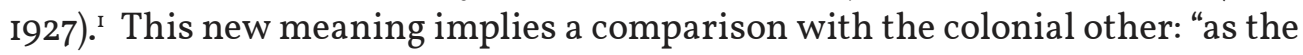
Ethnologists saw African fetishism as unproductive, degenerate, childish, primitive, and worthless, doctors and psychologists in the late nineteenth century used the same attributes to construct sexual fetishism as perverse" (Böhme 20I4, 297). Sexual fetishes are important to the history of the term and when one thinks of fetishism, sexuality is likely what first comes to mind, linked to the idea of deviancy. Sexual fetishes are out of scope for this paper, but it is important to note that the fetish as sexual adds negative connotations of perversion onto a term already laden with critique of the colonial other.

Fetishism as described by Karl Marx is more germane, given his work's extensive influence on sociology and specifically on Latour. Critiques of capitalism are also important to the critical LIS scholarship this paper will draw on, which would not be possible without Marx. Writing in the I9th century, Marx borrowed the term fetish from religious studies to critique Western commodity culture. In Capital, Marx coined "commodity fetishism" to describe a specific form of reification, or the shift in relations from between people to between objects. ${ }^{2}$ Commodity fetishism makes the material appear mystical:

\footnotetext{
A commodity is therefore a mysterious thing, simply because in it the social character of men's labour appears to them as an objective character stamped upon the product of that labour; because the relation of the producers to the sum total of their own labour is presented to them as a social relation, existing not between themselves, but between the products of their labour. This is the reason why the products of labour become commodities, social things whose qualities are at the same time perceptible and imperceptible by the senses. (Marx I887, I:47-48)
}

I. Freud characterizes fetishism as solely a male predilection, which is interesting in light of the roots of contemporary technology in male-dominated Silicon Valley.

2. Böhme notes that reification in German is ver-dinglichung, or literally rethingification (6). 
Marx viewed commodity fetishism as absurd because it imbues social life into objects as displaced from humans. A contemporary example to illustrate this would be how the development and production of a new model of iPhone requires intensive labour that is opaque to the consumer. Once on the market, the iPhone is no longer in relation with the workers but with other commodities, where it is compared against other smart phones for appeal and price. Fetishism is how "capitalism immediately presents itself to most people," which is why luxury items like new models of smart phones are easily understood as covetable items and status symbols (Gose and Paulson 20I7, IO7). Marx's concept of fetishism remains important, a critique of Modernity that flips on its head a term that was originally, during colonization and the Enlightenment, a denigration of colonised societies. Latour also uses the concept of fetishism to critique Modernity, focusing on scientific knowledge and the socially constructed nature of reality.

\section{Latour's Critique of Fetishism}

Bruno Latour's On the Modern Cult of the Factish Gods (2010) is an important recent critique of fetishism. Latour is a French sociologist and theorist in the field of science and technology studies. Like Marx, Latour uses the term "fetish" to critique Modern society, shifting the meaning from a term that denigrates the colonial other to analyzing the "otherness of ourselves" (Böhme 20I4, 7, emphasis in original). Latour argues that the Moderns, or those from the Enlightenment on, have insisted on dividing reality: into subject and object, human and non-human, self and other, and nature and society (2010). At the core of this separation is the Modern denial of the impact of non-humans, a category that for Latour includes "living entities, artefacts and machines, networks, technical infrastructure and material institutions" (Böhme 20I4, 50). In practicing fetishism, such as with the carving of an idol, individuals living in colonized societies ritualistically enact the comingling of human and nonhuman agency; the Moderns denigrate them for it. By contrast, Latour argues that human and nonhuman entanglement is neither deviant nor primitive, but an unseen fact of life hidden by the Modernist worldview.

The idea that non-humans co-construct reality with humans is central to Latour's work and worth exploring in more detail. Latour uses the example of Louis Pasteur and his work on bacterial culture to exemplify this entanglement. ${ }^{3}$ Pasteur constructs the laboratory settings that enable his object of study, yeast, to grow and change. The data collected about the yeast informs Pasteur and leads to the revelation of scientific facts for humanity. This is why for Pasteur, "constructivism and realism are 3. Pasteur is a favourite example of Latour's, and a bold one, because of Pasteur's importance to French culture and the history of science. See also: Latour, Bruno. 1993. "Pasteur on Lactic Acid Yeast: A Partial Semiotic Analysis." Configurations I (I): 129-46. https://doi.org/IO.I353/con.1993.0004; and, Latour, Bruno. 1999. Pandora's Hope: Essays on the Reality of Science Studies. Cambridge, Mass: Harvard University Press. 
synonymous terms. Facts are fabricated" (2010, I8). Pasteur writes as much in his own memoirs: his scientific work is objective because it is carefully controlled (2010, I7-I8). Latour insists that non-humans be taken into account in our understanding of the world, including the impact of their actions - as the yeast impacts Pasteur through its transformations.

Latour suggests we replace the Modern conception of individual humans acting alone, typified in myths of discovery and solitary scientific genius, with a worldview that sees humans and non-humans as entangled in networks of action. He describes this idea in detail with his work on actor-network theory, which posits that humans and non-humans form part of the same continuum, each capable of action, each working within networks, and each able to impact or do work through one another. ${ }^{4}$ In actor-networks an "actant" is what does an action (Latour 1999, 303), bypassing "the subject-object distinction" (308). In partnerships like this, it is nearly impossible to tell where the non-human ends and the human begins, as both function through networks. Actor-network theory critiques "the assumption of a pure and essential distinction between things and people" and replaces it with "the recognition that people and things are forever entangled with each other" (346). We are all members of a "collective" composed of different kinds of actants that affect one another in turn, through chains of action (Latour 1999, 304). Our actions are "hybrid" in nature, a mix of human and non-human work (Latour 1992, 154). Agency is enacted fluidly within these collectives and what agency non-humans have exists in relation to humans: "Agency is not held, it is not a property of persons or things; rather, agency is an enactment, a matter of possibilities for reconfiguring entanglements" (Barad 20I2, para. I2). Latour's work characterizes relations in a way that stands in contrast to the idea of societies composed solely of people (Latour 1999, 304).

This idea of entanglement is why in On the Modern Cult of the Factish Gods (2010) Latour critiques the Modern anti-fetishists as absurd. Latour states that in the Modern, Western world, facts are venerated instead of idols - we can extend this to say that science is venerated. 5 Yet facts, like carved idols, are constructed. The Moderns create facts just as those in fetishistic religions carve sacred objects. There

4. Co-created between Latour and Michael Callon, the legacy of actor-network theory is complex. Latour responded to issues with the term, which he saw as being misapplied, by denouncing it as a theory in 1997 but reinstated use of it in 2005. Despite shifts in the use of actor-network theory, its conceptual core, the entanglement of humans and non-humans and the defining importance of hybrid relationships, has remained the definitive characteristic of Latour's work. This informs Latour's work on fetishism. In On the Modern Cult of the Factish Gods, actor-network theory is not named even though it provides an essential conceptual backing. Actor-network theory is described here because of its importance as a theory within LIS.

5. Susan Leigh Star's note that "it is indicative of the central place of science in mainstream Western belief systems that merely to imply that the acquisition of scientific knowledge is work, not revelation" is revolutionary (Star 1995, 9). 
is no contradiction between the discovery of scientific facts and their creation, as objective reality exists, and the facts were there all along waiting for humanity to reveal them. The contradiction for Latour is that the Moderns deny this coconstruction of reality: "they deny to the objects they fabricate the autonomy they have given them" (2010, 6I). In other words, the Moderns as anti-fetishists cannot see facts as constructed and so worship them as magically arising. This is a thoroughly irrational position and one which is itself fetishistic in nature.

This position is also an advantageous one for the exercise of power. Their exclusionary worldview allows the Moderns to imagine that non-humans are dead subjects with no agency of their own. This pushes non-humans "back into a chain of causality that does not 'say' anything, does not 'mean' anything" and allows us to "control and predict them," an advantageous position for material domination (Böhme 20I4, 3). The concept of the fetish as a "racist myth" enabled the colonial exploitation of Indigenous lands (Latour 2010, I30, footnote I2) and it continues to enable capitalist exploitation. In the narrative of the fetish, Latour's work links the "discovery" of lands and peoples for colonization with scientific discovery, both of which have been used to place the other, or the Indigenous people of colonized lands, under Modernist control. This domination is aided by the invisibility of fetishism, given that the Moderns claim to be anti-fetishistic and so can imagine that their worldview is objective, neutral, and unconnected to their human desires as colonial invaders. Latour argues that humans have so thoroughly divided society and nature, and denied nature her agency, that climate change denial is paradigmatic of the Modernist worldview. Modernists do not see how this planet could gravely impact humans by becoming inhospitable despite all of the supporting evidence. ${ }^{6}$ Fetishism is a powerful tool for obscuring the origins of action and for extending domination.

The concept of the fetish will now be explored in more detail as it relates to academic libraries, first through a literature review to provide context and then an analysis of technology fetishism.

\section{Library and Information Science Literature Review}

Critiques of fetishism in LIS literature include the fetishizing of privacy (Fuchs 2OII), theory (Avison and Malaurent 20I4), peer-review (Derricourt 20I2), efficiency (Budd 2007), idealized spaces (Santamaria 2020), and scheduling (Peters 201I). These works differ in their critical approach and some authors, like Peters, apply the term "fetish" casually. There is also an underlying belief in the sacred nature of books and print materials in the literature (Santamaria 2020, 437) that has been critiqued in favour of futurism (Mathews 20I4). Futurism and the excessive focus within the literature 6. Latour's recent work Down to Earth focuses on climate change, and he sees the concept of human/ non-human entanglement as a narrative remedy to climate change denial (2018). 
on technology has in turn been critiqued as an ineffective panacea, a cure-all for contemporary library issues (Seale and Mirza 20I9; Grace and Sen 20I3; Manoff 20I5). This article builds on these critiques of technology to address a gap in the LIS literature on technology fetishism.

LIS scholars have referenced Latour to critique the philosophy of information (Star 1995), how form and interface influence use (Manoff 2015; 2006), scholarly communication networks (Beagle 200I), library instruction (Schreiber 20I9; Lihosit 20I4) and critiques of technology, data networks, and human computer interaction (Fleischmann 2007b; 2007a; Kaghan and Bowker 200I). Actor-network theory has been particularly influential for authors who have used it as a methodology to explore topics in depth. The field of science and technology studies has been influential on object discourse in general and "many thinkers have embraced materialist approaches" (Manoff 2015, 515). One-off quotations of Latour by Reidsma (2016), or Latourian statements such as those by Allison-Cassin that "humans are nodes within a network of relationships that include numerous living and nonliving actors" (415) are indicative of this broad influence. Wheeler argues that Latour's work is essential reading for a practical field such as LIS because it "informs our daily interactions" and "explores the very challenge we most have, accounting for human and non-human interaction" (19I). Typically, authors who draw on the work of Latour also advocate for the increased adoption of his work as a conceptual framework; this article reiterates this call.

The discipline of science and technology studies has done significant work in questioning and complicating scientific objectivity (Kofman 20I8). Despite this work, the claims of "communalism, universalism, disinterestedness, and organized skepticism," long critiqued by science and technology studies scholars still "remain commonly accepted in popular discourse" (Fleischmann 2007b, 4I4). This trust in science as objective is also broadly accepted in librarianship, which has presented itself as a scientific field (Fleischmann $2007 \mathrm{~b}, 4 \mathrm{I} 4$ ) with empiricism and positivism as the normative epistemologies (Hjørland 2005). As a result, more weight is given to knowledge produced by means of quantitative methods and numeric data, with the misunderstanding that these are neutral tools - their built in biases and engrained ideologies unexamined (Magnus, Belanger, and Faber 20I8). Priority is given to "that which can be counted over what can be understood in more complex ways" (Drabinski 2019). Critical librarianship, or LIS scholarship that questions "how library structures came to be and what ideologies underpin them," counters myths of scientific objectivity, but this is a substantial task given how engrained it is in the profession and in Modernist culture at large (Drabinski 2019). Latour offers a useful model for understanding the socially constructed nature of information, the comprehension of which can only strengthen scientific practice, including librarianship. By 
situating knowledge to recognize and overcome ingrained bias, we can construct the conditions required to be objective in our work. This is why Latour and his colleagues have always considered themselves "allies" of science whose work improved the practice, rather than as the enemies of science they have sometimes been depicted to be (Kofman 20I8, para. 3). This paper counters the popular and often unquestioned ideology that science and technology are always inherently objective or neutral, and instead explores technology fetishism to show how materiality is always entangled with human thought and feeling.

\section{Modern Technology Fetishism in Academic Libraries}

As Latour's position shows, Modern fetishes exist because of the denial of nonhumans, our silent partners in action. This denial has also led to the dispersal of fetishes into everyday culture. In Fetishism and Culture, Hartmut Böhme describes how the energy that might have once gone towards religious ritual and the creation of socially important fetishes in pre-colonial societies is now dispersed into everyday life, from personal consumption to cultural spectacles $(2014,8)$. Our societal energy is directed towards fetishistic practices, for instance, in the reverence held for sports paraphernalia or the rise in popularity of YouTube unboxing videos. Much of this focus is directed towards technology as the embodiment of humanity's innovative spirit (Arregui 20II, 49), making everyday devices appear mystical and giving companies like Apple or SpaceX cult-like followings.

Technology fetishism is exemplary among contemporary distributed fetishes because the language used to describe it serves as proof of how fetishism is enacted (20II, 5I). As explained by Aníbal García Arregui, technology is spoken of as both process and product. For instance, "German engineering" is both an action, e.g. the building of a car engine, and the result of this action, e.g. the engine itself. As product and process, technology is both "the symbol and the symbolized," which concretizes its "mystic energy" (54) and obscures the labour and material conditions that underlie it. 7 The dialectical "fuzziness" that occurs when we talk about technology enforces its fetishistic nature and blurs the lines of agency between human and non-human, making it unclear whether technology serves humans or we serve it (56). The blurring of meaning described by Arregui that gives technology its mystic veneer, or sense of "magic," is produced by hidden labour. This is the same effect that occurs when patrons praise librarians for "magically" producing information, unaware of the complex organizational infrastructure and skill that underpin this labour.

7. Similarly the etymology of "fetish" from the Portuguese means both "to do, to make" and "artificial, fabricated, factitious and finally, enchanted" (Latour 20IO, 3). 
Technology fetishism is particularly relevant for libraries because all roles within the profession "touch on some form of mediation of information within technological systems" and a major focus of library literature concerns "smoothing" this mediation (Allison-Cassin 2020, 4IO-II). Academic libraries have turned this to their advantage, using the fetish to gain prestige and prove their value, a necessity in the neoliberal context of higher education. Technology fetishism has manifested in academic libraries in the overuse of words like "innovative" in strategic planning documents (Schmidt 20I8, 5). This term lacks substance, gesturing towards a surface-level of meaning that can be used for marketing purposes unrelated to real technological work. ${ }^{8}$ Its meaning is slippery, containing "enigmatic mythologies" of human advancement, white-collar creativity, and efficiency achieved through a new device or app (Leary 2015, para. I). Innovation is also emblematic of the "normative" status of continuous change within academic libraries (Nicholson 2015, 33I-32) as innovation suggests unstopping improvement. Ongoing change leaves little time and energy for maintaining existing technology, which does not require innovation but does need upkeep (Russell and Vinsel 20I6). Technology infrastructure such as ILS systems go unmaintained when the strategic planning focus of academic libraries is directed towards innovation for the sake of gaining prestige.

In addition to using technology buzzwords for prestige in marketing, academic libraries also fetishize technology as a tool of professionalism. Seale and Mirza argue that this is evident in discussions about credentialing and the suggestion that the MLS degree be replaced with code school (Seale and Mirza 2019, 262). Traditional librarianship practices like reference services are deemphasized, while technology is emphasized; the prestige is what is at issue here, rather than any actual benefits of coding itself. Seale and Mirza also point to specific initiatives as proof of this focus, such as the American Library Association's (ALA) Center for the Future of Libraries, which almost exclusively publishes trends that partake in "internet-centrism" or digital solutions that despite their revolutionary, world-changing nature depict the Internet as stable, inevitable, and outside of history (2020, I75). An example of internet-centrism is how powerful internet companies harvest huge amounts of personal data from citizens, and this is popularly understood to be inevitable even though it could be prevented with government regulation. Examples of internetcentric technology on the ALA website include blockchain, drones, and gamification, all over-hyped words with diminished meaning from overuse (American Library Association 2020). LIS literature has also included an undue amount of energy and focus on specific technology acquisitions, such as 3D printers and visualization

8. Words with a surface level of meaning that are rhetorically useful can also be called bullshit, and innovation is "business bullshit" (Schmidt 20I8, 5). 
immersion studios. ${ }^{9}$ As academic libraries work to prove their worth, technology fetishism is an appealing strategy for legitimization and prestige in capitalistic economies.

Technology fetishism also feeds into "technocratic solutionism" (Seale and Mirza 20I9, 262), rhetoric that "promotes the assumption that any problem can be solved with the right tool" (Manoff 2015, 523). Technocratic solutionism depicts technology as rational, progressive, and bringing about necessary change (Seale and Mirza 2020, I76). The use of this rhetoric is powerful and profitable. Google, for instance, has encouraged myths about its power through marketing that depicts it as an answer machine, public statements about its objectivity, and design aesthetics that reinforce this point. ${ }^{\text {Io }}$ To "Google it" is to find the answer, which is process and product in one.

It is worth paying attention to Google because it is often held up in comparison to libraries. Google is considered a threat to libraries because it provides access to large amounts of information, and so "in local communities where libraries are threatened with closure, the general public sensibility is, 'what do we need the library for when we have Google?"” (Reser, McNeill, and Ortenberg 20I8). This threat is also directed against academic libraries, where the sentiment of patrons is that everything is available for free online. The uneven comparison between Google and libraries pits the technological against the analog, where innovations like Google Books are popularly viewed to have killed off libraries filled with print books (Settoducato 20I9, para. I). Out of a perceived need to compete, libraries have adopted Google-like discovery layers, which are unified indexes that combine catalogue and database searching into a single search box prominently located on the homepage of a library website (Widdicombe 2003).

Discovery layers demonstrate the irrationality of technology fetishism well through their screen-like veneer of meaning and material transcendence. They are worth exploring as a specific example of technology fetishism in academic libraries. Discovery layers are often named in a way that overstates their capabilities as portals

9. These technologies are often included in makerspaces. In makerspaces, craftsmanship is fetishized through "making," often by using technology to update traditionally female crafts, such as art-making with digital embroidery machines. Fetishism in makerspaces is beyond the scope of this paper but an interesting area for future research related to fetishism and gender.

IO. Google markets itself as an answer machine through their own explanations of how search works, stating that algorithmic ranking makes "finding what you need" simple (Google n.d.). In public statements, Google has repeatedly claimed objectivity (Reidsma 20I9, 36). Google's aesthetics reinforce this point, as argued by Safiya Noble: "When you go to Google, it's just a simple box against a simple background. And that conveys, through its aesthetic, the idea that there's nothing going on. Its design logic is so simple: type in a word, and you'll get something back" (Noble and Roberts 20I8, para. I8). Google's initial success was the result of its original relevancy ranking algorithm, intended to provide answers, which has since become widely mimicked by competing search engines and vastly expanded upon, defining the market for search engines (Levesque 2019, para. 15). The success of Google is why this article focuses on it to the exclusion of other search engines. 
to knowledge. "I They operate as "black boxes," meaning that the algorithm that connects a search to a set of results is hidden; answers seem to magically appear. When a patron initiates a search within the discovery layer, they begin down a maze to acquire an item, sometimes jumping between several vendor pages, databases, and linking services to do so. When they finally reach their goal, the journey has made it so they "cannot tell the difference between distinctly different resources" (Jablonski 200I, I3I). Discovery layers flatten information, juxtaposing articles from Nature, print fiction, and local news: "all discourse becomes smoothed out and equal in the library information system" (Allison-Cassin 2020, 4I8). ${ }^{12}$ Searching in this manner creates the sense that all resources are both immaterial and only a click away. As a liaison librarian, I have often helped patrons in their urgent search for PDFs who cannot identify what that PDF represents - an article? a thesis? - and who were stumped by a record for a book, its physicality standing in contrast to the search interface that decontextualizes and dematerializes resources.

As a tool, discovery layers are usually conceived of as immaterial despite the fact that they are very physical indeed, requiring a computer and a human who can use it, to say nothing of the physical nature of server farms, vendor offices, and the library workers who create the network a searcher operates within. An actor-network theory approach to discovery layers indicates that they are composed of numerous actants, including non-human material components like hardware and software that shape search. The physicality of the actants involved is conceptually obscured by the seamless nature of discovery, which transcends and obscures materiality in its offerings of instant answers. This is because in digital environments like discovery, "the physical world seems to be relegated to the past," and we easily forget about the server farms, organizational infrastructure, and human labour that underlie library work until they break down (Popowich 2019, I65). This dematerialization impacts how library labour is perceived, as "narratives of the high-speed virtual library, with its seamless interfaces, instant access, and 'frictionless' interactions, obscure the temporal labor of library workers" (Nicholson 20I8, I6). The discovery layer is an example of how library labour acts as a "modality without a presence," a construction and maintenance of infrastructure that goes unacknowledged (Rhodes, Richardson, and Trent 20I8, 6). Library work is invisible for the searcher, hidden behind the discovery layer.

II. The Ontario consortia OCUL offers a discovery search available at I4 member libraries called "Omni," a term which denotes universality and connotes omniscience (Pagotto 2019). The discovery system at Geneseo SUNY formerly had the tagline "research made easy," which Galvan argues was misleading because research is not easy (Galvan 20I6, para. II). The name "discovery layer" itself connotes revelation, matching Modernist myths of scientific discovery and ownership.

I2. The way that social media juxtaposes news, opinion, and celebrity updates has been called "content collapse," and the same phenomenon occurs within discovery layers (Carr 2O2O). 
What matters for patrons using the interface is only to find an answer, and the nature of the interface guarantees that they will find something closely resembling one. Confirmation bias shapes how information is perceived, causing researchers to pay more attention to the results supporting their pre-conceived beliefs than those that do not. Nearly any search in a discovery layer will produce a high number of results, which creates confirmation bias for users (Manoff 2015, 520). Library patrons who have been using Google for years have also been taught "trust bias," meaning that the results they find gain the appearance of legitimacy (Asher 2015). This occurs because Google is highly effective at producing relevant results in many situations, such as providing the location of a nearby coffee shop. Trust bias trains researchers who regularly use Google, and as they use a discovery layer they develop trust bias with this system as well. Since a discovery interface is more complex to use than Google, and patrons often do not possess the skills required to navigate it (Manoff 20I5, 52I), this creates a greater reliance on the initial results and ranking, called interface bias. ${ }^{13}$ The confirmation, trust, and interface biases present for patrons is further shaped by the discovery layer's algorithm: different discovery layers preference different format types above others and have different functionality, meaning that the nature of the tool determines what resources are found and used (Manoff 2015, 52I, 517). Although librarians can make minor customizations to discovery layers, as third-party tools these modifications are minimal, and changes that enhance relevancy such as eliminating book reviews from search results risk enhancing fetishism. The relevancy of the result set is further ensured for researchers by the urgency of the need for answers. Higher education as a business has sped up the experience of time for the searcher and changed the messiness of research into a standardized format through "McDonaldization" (Nicholson 20I8, I6). In this way, the discovery search reduces the complex task of research into a very simple one. Searchers take the results they find, "cobble" them together, and "move on to the next task" (Widdicombe 2003, 194). Inherent bias, the search interface, and the speed of research combine to create a fetishized discovery system where results appear as answers.

Librarians should be concerned with how discovery layers significantly shape research output. Although "discovery's promise of a simple search experience works for users, more often than not" (Reidsma 20I6, para. 2), the effects of discovery on research writ large are as yet unknown. It is a reasonable assumption that because discovery layers quickly deliver what appear to be relevant results, they diminish researchers' critical evaluation skills and work against careful, slow scholarship. The invisibility of library labour that I have described becomes a greater threat the I3. To further complicate matters, the algorithms that underlie search are not static but always changing based on nuance of input and usage feedback that results in software developments (Reidsma 2019, I7). As a responsive tool, search shapes researchers and researchers in turn shape search. 
more that seamless access increases and our reliance on technology deepens. Regular improvement to databases like Google Scholar, which builds on the foundation of Google but competes directly with library discovery layers, further removes users from the academic library altogether. Through Google Scholar, access to material is directly available for patrons via library subscriptions but without the library name or logo made visible, except in a miniscule link resolver button. It is difficult to advocate for stable library jobs when patrons perceive information to be immaterial and their point of access is through a branded, third-party service-be it Google Scholar or library discovery.

Another result of relying on third-party vendors to provide access to resources is the disappearance of academic libraries as an essential node in the scholarly communication network. In his actor-network theory analysis, Donald Beagle traces how vendors have increasingly inserted themselves into scholarly communication over time, edging out libraries whenever a vacuum of power appears. Writing in 200I, Beagle envisioned that when vendors controlled the traditional library work of indexing, aggregation, and preservation, they would fully replace librarians in this network (430). Discovery layers include the first two of these major functions. The increased control over the scholarly technical network is, of course, purposeful, as it holds advantages for vendors. The owner of a discovery layer can prioritize linking to the databases that they also own (Galvan 20I6, para. II), surveil users at all points in their search, and monopolize the scholarly research market. The important role discovery layers play in shaping research shows the embeddedness of vendors, limiting the autonomy of academic libraries and a collective move to an open access model of scholarship.

As the next section of this article will describe, librarians should also be concerned about how search embeds and legitimates dominant systems of power through racist and sexist content, outputting it directly to researchers.

\section{Examining the Invisible and Tracing Power through Technology Fetishism}

The purpose of critiquing fetishism is not to argue against the use of technology in libraries-I am not suggesting that we give up the use of technology, which plays a central role in academic libraries. It is not about "shattering idols," but redirecting attention and energy away from harmful attachments towards more useful ones (Latour 20IO, 6I). The purpose of this critique is also to allow library workers to see academic libraries more clearly and make decisions based on all of the available evidence, rather than leaving one-half, that concerned with non-humans, unseen. Tracing the origins of non-humans and their effects is powerful because the 
contemporary fetish, by being distributed, is hidden from sight. Focusing on nonhumans is necessary to understand the full picture of hybrid labour: "To understand the activity of subjects, their emotions, their passions, we must turn our attention to that which attaches and activates them-an obvious proposition but one normally overlooked" (Latour 20I0, 58). Untangling the relationships between actors and following the networks non-humans are embedded in causes us to consider a materiality that was previously hidden, allowing us to choose our attachments.

To return to my earlier example of discovery systems as fetish objects, an analysis that traces the networks of these tools shows that they are connected to dominant systems of power. For keyword searching, engrained bias is a problem for both discovery layers and Google, which have been proven to contain societal biases, including racism and sexism (Reidsma 2016; 2019; Noble 2018). This is because "algorithms are shaped by the judgments and theoretical assumptions of their designers," meaning the white men of Silicon Valley who are the primary engineers of such systems (Manoff 2015, 520). This is also because search algorithms are "fundamentally connected to the categories that organize library catalogs" (Adler 20I7, 4). When Melissa Adler traces the origins of controlled vocabulary, a key component of library cataloguing, she finds the racist context of its production and traces this to its current iteration. This embedded bias in controlled vocabulary is all the more entrenched for being unexamined (Adler 2017). Their "invisibility and ubiquity" as well as how vocabulary are made to appear as naturally occurring rather than as deliberate choices, "heightens their potency and secures their ground" (23). Adler is able to name the specific nineteenth century cataloguers she holds culpable, but in the case of the algorithmic bias analysis identified by Reidsma and Noble the engineers themselves are nameless, subsumed within the brand name of a company, and the algorithms they produce are black boxed. Both cataloguing and search operate within a network that recreates racism and sexism through non-human actants, and so, influence patrons when they navigate a catalogue or search online. As an example, Adler describes how content about Black Americans has historically been catalogued under a special class separate from that of other American citizens (I8). It is possible to draw a line of racist indexing practices from these subject headings to the representation of Black Americans in Google, where an image search for "three white teenagers" brings up photos of smiling faces and a search for "three black teenagers" brings up photos of mugshots (4). In both instances, Black Americans are othered and a naïve searcher may be led to believe that Black Americans are inherently criminal, separate from other upstanding citizens. Today's cataloguing practices continue a chain of oppressive action that has been carried out for over a century. 
Embedded bias is exposed by researchers who have carefully reverse engineered search results and traced the lineage of classificatory terms. Doing so exposes the actants that shape research and how social relations are embedded in non-humans, undermining the idea that search is "neutral." According to Seale and Mirza, the positioning of technology as a neutral good is only possible if we imagine the end user perspective to be that of a white male-the hegemonic norm of our white supremacist, patriarchal Modern world (Seale and Mirza 2020). The experience of search is not crafted for users from marginalized groups, for whom sexist and racist search results can be a jarring reminder of oppression. ${ }^{14}$ In the Google image search of "three black teenagers," the mugshots shown would be a bitter reminder to Black researchers of the racist oppression that takes place through the criminal justice system and the perception of Blackness as tied to criminality. Libraries partake in the prestige of technology through the use of terms like innovative-which connotes masculinity along with technology (Seale and Mirza 2019, 257)-and uphold this end user as an imagined ideal. By tracing the sociotechnical networks that produce search results we find that they include a multitude of actants, human and non-human, at odds with the idea of neutral good. This includes:

the mining of metals used in computer components in the Democratic Republic of Congo and Mongolia, the assembly of computers and other devices in China, the filtering of social media performed by workers in the Philippines, the technical support provided by call center workers in India and the Philippines, the disposal and recycling of technological equipment in China and Ghana, and so on. (Seale and Mirza 2020, I80-I8I)

The exploitative labour in these relationships tilt agency towards the non-human, effacing the miner for the sake of the mined resources. The coupling of these two actants is enabled by Modernist fetishism, where the non-Western subject is othered for the sake of material extraction. The focus in Western conceptions of technology's gains is on the benefits of mining, recycling, and support for the end user, assumed white and male, to the exclusion of other, subjugated human beings (I8I). ${ }^{15}$

The biases hidden in our sociotechnical networks are often explained away as implicit, as if that excuses them-when what is hidden can be much more pernicious for being unseen. Studying fetishes allows "us to grasp more precisely our own sciences and technologies" and determine the source of the "domination" they exert over us (Latour 20I0, 66). Technology can be used to effectively advance agendas,

I4. See the chapter "Searching for Black Girls" in Algorithms of Oppression for examples of these experiences (Noble 20I8).

15. White supremacy is embedded into institutions and carried out through non-humans as seemingly neutral actors. This article has focused on technology in libraries, but the study of non-humans as tools of marginalization is an extensive project. Without calling them as such, Eino Sierpe lists a number of non-human actors he argues maintain white supremacy in librarianship, including professional standards, professional gatherings such as annual conferences, subject headings, building and interior design, and collections, including how they are defined, built, managed, cataloged, organized and their content communicated (Sierpe 2019, 88-89). 
such as those of whiteness and patriarchy, and it can do so because of our inability to see non-humans and their role in labour: "The processing of machines is in the background, intentionally invisible and silent" (Allison-Cassin 2O2O, 4II).

Technology can also be used to gain control over labour. This is the case with McDonaldization, which realizes efficiency "through the substitution of technology for human labour" where "the increasing use of technology in libraries serves as a mechanism of rationalization and control" (Nicholson 2015, 328). It also occurs with the subsumption of immaterial labour into capitalism (Popowich 2019). Immaterial labor is "the intellectual, emotional, and affective work we have always done, but which only became a site of direct exploitation (i.e., considered productive rather than unproductive labor) with the development of a certain level of automation, computerization, and digital communications technologies" (I56). Sam Popowich uses the example of the replacement of in person services with online chat reference to illustrate how this occurs in academic libraries (154). Another example could be the replacement of evaluative literacy skills with discovery layer relevancy. Intellectual labour is often traditionally female labour, and in a library context this includes reference and instruction (Emmelhainz, Pappas, and Seale 20I7). Because it is gendered, this work is undervalued, which makes it an easy target for innovation. The subsumption of intellectual labour into capital through technology effectively recodes it as male, thus enhancing its value and its potential for exploitation. Through this process the work is also changed significantly, incorporating new elements of control such as surveillance - consider timestamped online chat logs - and the replacement of complex communication with simple text dialogue. Online reference is well suited for lookup queries, but it does not have the depth and nuance of inperson discussion. Nonetheless, online reference, like discovery, maintains a veneer of comprehensiveness and appeal through the means of the fetish.

Through reification, technology is then used to hide that this exploitation is purposeful, driven by the need of capitalism to continually find new sources of labour. Popowich writes that: "By placing the responsibility for technological change within libraries on inanimate objects (the network, or the digital environment), the technological changes we experience appear as outside our control: people do not make them happen, they happen on their own" (2019, I66). This makes work activities that occur outside of work hours, such as checking email or posting to social media, appear "natural, unavoidable, and inevitable" (I66). This is an example of what might be called the "boomerang logic" of "technototemism" where "social relations are transferred into nature or technological world, and then nature (or technology) can be transferred back to legitimate an existing social order as the natural order" (Hess I995, 23). This method to legitimize the demand for increased labour through 
a technological medium is why the fetish is an appealing tool for capitalism. Technototemism is closely linked to the idea of "technological solutionism," because both make technological progress appear inevitable. The effect of this is that technology fetishism drives academic library work while remaining unseen, and so, unquestioned. This is what drives the focus in libraries on innovation while obscuring its origins in higher education neoliberalism.

However, technological progress is not inevitable, and its real effects should be examined in order to separate its magical conception from base reality. It is emphatically not true that technology can be used to solve any problem, as confirmed by a list published by The Verge of 84 major technological failures that have occurred in the past decade (The Verge 20I9). These include flops like Google Glass that attempted to solve a complex issue (maintaining human relationships) with a simple solution (surveillance glasses) or Theranos (venture capital backed blood tests) that lacked physical technology altogether and was composed solely of magical-thinking. This list was written in order to amuse readers and draw these companies some welldeserved scorn, but technological solutionism can have serious effects. For example, at Millennium Library in Winnipeg, security screening was implemented in response to the perceived threat of violence from patrons. Brianne Selman and Joe Curnow argue that there was no threat to workers initially, only a perceived fear. When security screening was implemented this put patrons at risk of violence, as screening increases conflict, criminalization, and marginalization (Selman and Curnow 2019, $2-3)$. In this case, imagined violence became manifest, directed at patrons in an attempt to protect staff. At Millennium Library, "marginalized patrons have literally been pushed out into the cold" (2). The real, material effects of non-human action, such as how security infrastructure marginalizes Winnipeg public library patrons, serves as proof of their imbued agency. This is only one example of the material impact of technology fetishism, which also includes the ostracism of women from technology professions, ${ }^{16}$ the lower wages earned by women performing emotional labour compared to men working in systems roles (Popowich 2019, I6I), and the pivot of higher education towards fetish objects like entrepreneurial technology labs and away from other worthy projects.

These examples illustrate how technology is entangled with systems of power. Nonetheless, the myth of library neutrality is still prevalent and "the dominant discourse of librarianship resists the idea that the profession in any way sets, modifies, or controls any aspect of our users' immaterial or cultural lives" (Popowich

I6. To prove that this is occurring, D'Ignazio and Klein describe history of computing as a female field that has been overtaken by men as it has grown more prestigious. They describe the career of Christine Darden, one of several black female computer engineers who accomplished remarkable work at NASA but has been absent from its legacy. They also chart the diminishing number of women receiving computer science degrees in the second half of the 2oth century (I-I9, 27). 
2019, I60). Focusing on the networks that our technological actors are embedded in, and exposing the non-neutrality of technology, refutes this myth. Libraries are "participants in culture" and "digital libraries are part of complex sociotechnical actor networks" (Fleischman 4I3, 420). However, libraries cannot realize their agency without first acknowledging that they are embedded in networks, in systems of power, and cannot do so while relying on the prestige technology fetishism affords.

The worldview that sees non-humans as invisible and inanimate allows for them to work unseen. Technological non-humans are nodes in patriarchal and white supremacist networks: they derive from these worldviews and do work for it. To Latour, the flaw with Modernism lies in the dichotomy of human and non-human, object and subject (2010). This worldview necessarily limits one's ability to see a full picture of the world that includes all of the relevant actants, and "under the now dispelled fantasy of the fetish, the enlightened human being realizes that he is not really alone, but that he shares his existence with a crowd of actors" (Latour 20IO, IO). Academic libraries must break free of this worldview that sees objects as either dead and unfeeling, or elevated to the status of magical fetish, if we are to properly see technology and reorient its effects.

\section{Seeking Alternatives to Technology Fetishism}

We have seen the potential for harm when the role of non-human actors is dispersed and obscured: from search that foregrounds racist and sexist content, to information systems that fail patrons and the research process, to library labour that is hidden, undervalued, and replaced. Solutions to technology fetishism in academic libraries are urgently needed. Technology advances rapidly and fetishism increases as "the projection of human qualities such as intelligence, personality, faithfulness or autonomy onto our machines becomes everyday more present" (Arregui 20II, 55).

The issues with technology fetishism that I have described disempower library workers, reducing and hiding their labour. It only makes sense that the solutions offered within the literature describe ways to empower, resist, and illuminate. With discovery layers, the suggestion is to open the black box (Manoff 2015; Noble 2018; Reidsma 20I6). This would enable a better understanding of what biases are hidden within search and by highlighting its complexity, enable librarians and patrons to see the work inherent in research; there is nothing magical about it. Allison-Cassin writes that this examination is needed to regain power: "We need to look at the source codes for patriarchy, capitalism, and colonialism, the conceptual maps underpinning these systems, and demand feminist and democratic systems that deploy technology in service to justice, not humans in service to technology" (428). It is possible that discovery layers could be reconfigured to create systems of inclusion rather than 
exclusion, and forge new networks, as Scarlet Galvan imagines: "What if a search for 'all lives matter' offered the Ferguson Archive as an option alongside the scholarly articles?" (Galvan 2019, IO2). Adler suggests that alternate classification arrangements can be found to those offered by the major schemas: "I am looking for more examples of everyday spaces where information is organized in ways that counter dominant narratives about race" (Adler 20I7, 27). Seeking inspiration from local sources, such as activist bookstores that represent their communities, could elevate new modes of classification that break from inherited chains of action.

What these reconfigurations suggest is that marginalized individuals who lack power within a network can be given power through non-human proxies: the source code, the Ferguson archive, the classification schema. Sweeping away the illusion of fetishism allows agency to be reclaimed and given to those within our networks who have previously been harmed most by fetishism's ill effects. This reclaiming need not be limited to labour enacted through non-humans. BIPOC (Black, Indigenous, People of Colour) library workers, women, and other individuals marginalized by technology need to be elevated to positions of power within sociotechnical networks. Specifically, academic libraries should employ technology experts who are BIPOC, women, or otherwise typically omitted from the power systems that favour white masculinity and incorporate strategies to enable the success of these individuals in thriving and enacting change. Doing so would require a radical shift for academic libraries, which are exclusionary spaces that reiterate and reinforce dominant norms (Sierpe 20I9). However, the effect of this could be to shift power in academic libraries and disrupt the flow of white supremacy and masculinity in knowledge networks.

I am also inspired by technology hybrids, such as those created between academic librarians and Indigenous scholars. These relationships produce cataloguing projects that foreground Indigenous voices and tailored technology that guards traditional knowledge; in other words, producing technology that services the needs of and does work for Indigenous scholars. ${ }^{17}$ This work stands in contrast to treating technology as a fetish, the conceptual origin of which is closely tied to colonial beliefs and oppressive strategies. In considering networks to examine and cultivate, academic librarians should heed Indigenous authors who invite nonindigenous individuals to reconsider the relationships we hold with one another and with the land, seeking a "radical relationality" freed from a mindset of commodification (Martineau and Ritskes 20I4, 6). The work of these scholars and their focus on decolonization reminds us that the Modern approach to non-humans of fetishism, alienation, and dominance is ultimately unsustainable and destructive. We cannot afford to deny that nonhumans have agency given the growing crisis of climate change.

I7. The University of British Columbia research guide on Indigenous Librarianship lists many of these hybrids (Xwi7xwa Library 2020). 


\section{Conclusion}

This article has traced the history of fetishism, from its origins as a concept developed during colonialism to its use by theorists like Marx to critique capitalism. Latour's work, following Marx, refutes the idea that the Modernist worldview is neutral and objective, and instead describes how it contains prejudices that shape how reality is perceived. The Moderns, Latour argues, have split the world in two, into subject and object, out of a denial of non-human agency. This has led to the creation of Modern fetishism, which imbues non-humans with a magical quality while also irrationally hiding that they are fetishes. The trick of the Modern fetish is to hide itself, making its effects appear natural, inevitable, and unaccountable. Fetishism is particularly pronounced in technology because of technology's association with human innovation and the role that it plays in upholding networks of hegemonic power. Given the importance of technology in academic libraries, examining technology fetishism is crucial, enabling an exploration of how academic libraries are entangled in oppressive networks of action that embed racism and sexism into academic work. Recognizing technology fetishism as such also allows academic libraries to consider alternative relationships with technology. This includes critical work focusing on technology's real function and effect, configuring new and more inclusive networks, and the creation of hybrids that break free from a Modernist worldview.

The most powerful idea that Latour offers for academic libraries is a radical reimagining of the world as populated by a vast number of entities where once it was considered to be empty except for humans alone. This major conceptual shift offers an alternative to technology fetishism by exposing the fetish as a construct, a narrative of obfuscation. Laying it bare allows librarians to view technology with a more critical eye. This paper has explored discovery layers as fetish objects, but it would be equally possible to apply a Latourian approach to critically analyze specific objects, such as archival memorabilia, for their problematic origins and negative impact, or to consider technology-centered spaces, such as makerspaces, for their fetishistic qualities. These are areas for further study and could be explored in relation to embedded racism and sexism in research processes and academic library work. In suggesting alternatives to technology fetishism, these reimaginings could prompt further research questions. Namely, who is included in your library socio-technical networks? What proxies for power are in your library? How do your patrons from marginalized groups see themselves represented in your library technology, and how are they excluded? These are key questions for academic libraries to assess. 
Academic libraries collect, organize, preserve, and enable the use of non-human actors. We cannot pretend that our objects do not have an impact on the world or that we are not participants in culture. By tracing the normally invisible, we find impactful non-humans. By examining fetishes, we find that they hide labour for the sake of a veneer of prestige. If academic libraries are to steer their own destinies, rather than be steered by technology and the interests of hegemonic norms, they must acknowledge their material entanglements and learn to recognize and seek alternatives to technology fetishism.

\section{ABOUT THE AUTHOR}

Lisa Levesque is an Evaluation and Assessment Librarian at Ryerson University Library. She holds an MLIS degree from the University of Western Ontario and an MA in English Literature from the University of Ottawa. Her recent research has included a critical analysis of the experiences of new librarians, qualitative studies of student research processes, evaluative web-literacy research, and research on library fines.

\section{REFERENCES}

Adler, Melissa. 2017. "Classification Along the Color Line: Excavating Racism in the Stacks." Journal of Critical Library and Information Studies I (I). journals.litwinbooks.com/index.php/jclis/article/ view/I7/IO

Allison-Cassin, Stacy. 2020. "Bodies, Brains, and Machines: An Exploration of the Relationship between the Material and Affective States of Librarians and Information Systems." Library Trends 68 (3): 409-30. doi.org/doi:IO.I353/lib.2020.0009

American Library Association. 2020. “Trends.” Future of the Library. Accessed April 27, 2020. perma. cc/T3GW-DJPD

Arregui, Aníbal García. 20II. “Too 'High’ Tech: Metonymical Fallacies and Fetishism in the Perception of Technology." Journal of Contemporary Anthropology II (I): I7.

Asher, Andrew D. 2015. "Search Epistemology: Teaching Students about Information Discovery." In Not Just Where to Click: Teaching Students How to Think about Information, edited by Troy A. Swanson and Heather Jagman, I39-I54. Chicago, IL: Association of College and Research Libraries.

Avison, David, and Julien Malaurent. 20I4. "Is Theory King?: Questioning the Theory Fetish in Information Systems." Journal of Information Technology 29 (4): 327-36. doi.org/IO.IO57/jit.2OI4.8

Barad, Karen. 20I2. “'Matter Feels, Converses, Suffers, Desires, Yearns and Remembers': Interview with Karen Barad." In New Materialism: Interviews \& Cartographies, edited by Rick Dolphijn and Iris van der Tuin. Open Humanities Press. dx.doi.org/I0.3998/ohp.II51570I.000I.OoI

Beagle, Donald. 20or. "The Sociotechnical Networks of Scholarly Communication." Portal: Libraries and the Academy I (4): 42I-43. doi.org/IO.I353/pla.200I.0060

Böhme, Hartmut. 20I4. Fetishism and Culture: A Different Theory of Modernity. Translated by Anna Galt. Berlin; Boston: De Gruyter.

Budd, John. 2007. "The Spellings Commission: Challenges to Higher Education and Academic Libraries." Portal: Libraries and the Academy 7 (2): 137-46. doi.org/I0.1353/pla.2007.0015

Carr, Nicholas. 2020. "From Context Collapse to Content Collapse." ROUGH TYPE. Last modified January I3, 2020. roughtype.com/?p=8724

Derricourt, Robin. 2012. "Peer Review: Fetishes, Fallacies, and Perceptions." Journal of Scholarly Publishing $43(2)$ : $137-47$. 
D’Ignazio, Catherine, and Lauren F. Klein. 2020. Data Feminism. Strong Ideas. Cambridge, Massachusetts: The MIT Press.

Drabinski, Emily. 20I9. "What Is Critical about Critical Librarianship?" Art Libraries Journal 44 (2): 49-57. doi.org/IO.IOI7/alj.2019.3

Emmelhainz, Celia, Erin Pappas, and Maura Seale. 20I7. "Behavioral Expectations for the Mommy Librarian: The Successful Reference Transaction as Emotional Labor." In Feminist Reference Desk: Concepts, Critiques, and Conversations, edited by Maria T. Accardi, 27-45. Sacramento, CA: Library Juice Press.

Fleischmann, Kenneth R. 2007a. "The Evolution of Agency: Spectra of Bioagency and Cyberagency." The Information Society 23 (5): 36I-7I. doi.org/I0.1080/0I972240701572897

Fleischmann, Kenneth R. 2007b. "Digital Libraries with Embedded Values: Combining Insights from LIS and Science and Technology Studies.” The Library Quarterly 77 (4): 409-27. doi.org/IO.I086/520997

Freud, Sigmund. 1927. "Fetishism." In Miscellaneous Papers, I888-1938, 5:198-204. London: Hogarth and Institute of Psycho-Analysis.

Fuchs, Christian. 20II. “Towards an Alternative Concept of Privacy.” Journal of Information, Communication and Ethics in Society 9 (4): 220-37. doi.org/IO.IIO8/1477996IIII9IO39

Galvan, Scarlet. 2019. "More Than Things." Serials Review 45 (3): 99-IO2. doi.org/IO.IO80/o0987913.2019.I 646080

- - 2016. "Architecture of Authority." Scarlet Fixes Things. Last modified December 5, 2016. asgalvan. com/2016/12/05/architecture-of-authority/

Google. n.d. "How Search Algorithms Work." Google. Accessed April 27, 2020. perma.cc/6JZS-79JZ

Gose, Peter, and Justin Paulson. 2017. “Capital and Its 'Laws of Motion': Determination, Paxis and the Human Science/Natural Science Question." In Reading Capital Today: Marx after I5O Years, edited by Ingo Schmidt and Carlo Fanelli, 97-II5. London: Pluto Press.

Grace, Dan, and Barbara Sen. 20I3. "Community Resilience and the Role of the Public Library." Library Trends 6I (3): 5I3-4I. doi.org/IO.I353/lib.20I3.0008

Hess, David J. 1995. Science and Technology in a Multicultural World: The Cultural Politics of Facts and Artifacts. Columbia University Press.

Hjørland, Birger. 2005. "Empiricism, Rationalism and Positivism in Library and Information Science." Journal of Documentation 6I (I): I30-55. doi.org/IO.II08/002204105IO578050

Jablonski, Jon. 200I. "Defining the Object of Study: Actants in Library and Information Science." Libri $5 \mathrm{I}$ (3). doi.org/IO.15I5/LIBR.200I.129

Kaghan, William N., and Geoffrey C. Bowker. 200I. "Out of Machine Age?: Complexity, Sociotechnical Systems and Actor Network Theory." Journal of Engineering and Technology Management I8 (3-4): 253-69. doi.org/IO.IOI6/So923-4748(OI)Ooo37-6

Kofman, Ava. 20I8. "Bruno Latour, the Post-Truth Philosopher, Mounts a Defense of Science." The New York Times, October 25, 20I8. nytimes.com/20I8/IO/25/magazine/bruno-latour-post-truthphilosopher-science.html

Latour, Bruno. 20I0. On the Modern Cult of the Factish Gods. Translated by Catherine Porter and Heather MacLean. Durham: Duke University Press.

- - 1999. Pandora's Hope: Essays on the Reality of Science Studies. Cambridge, Mass: Harvard University Press.

_- - I992. "Where Are the Missing Masses? A Sociology of a Few Mundane Artifacts." In Shaping Technology/Building Society: Studies in Sociotechnical Change, edited by Wiebe E. Bijker and John Law, 225-58. MIT Press. 
Leary, John Patrick. 2015. "Keywords for the Age of Austerity I: Innovation." Keywords: The New Language of Capitalism. Last modified April 3, 2015. keywordsforcapitalism.com/2015/04/o3/keywords-for-theage-of-austerity-I-innovation/

Levesque, Lisa. 2019. “Developing Evaluative Literacy Skills." In Digital Citizenship Toolkit. pressbooks. library.ryerson.ca/digcit/chapter/chapter-5-developing-evaluative-literacy-skills/

Lihosit, Judith. 20I4. "Breaking Down the Black Box: How Actor Network Theory Can Help Librarians Better Train Law Students in Legal Research Techniques.” Law Library Journal Io6 (2): II.

Magnus, Ebony, Jackie Belanger, and Maggie Faber. 2018. “Towards a Critical Assessment Practice." In the Library with the Lead Pipe. inthelibrarywiththeleadpipe.org/2018/towards-critical-assessmentpractice/

Manoff, Marlene. 2015. "Human and Machine Entanglement in the Digital Archive: Academic Libraries and Socio-Technical Change." Portal: Libraries and the Academy I5 (3): 513-30. doi.org/I0.1353/ pla.2015.0033

- - 2006. "The Materiality of Digital Collections: Theoretical and Historical Perspectives." Portal: Libraries and the Academy 6 (3): 3II-25. doi.org/IO.I353/pla.2006.0042

Martineau, Jarrett, and Eric Ritskes. 20I4. "Fugitive Indigeneity: Reclaiming the Terrain of Decolonial Struggle through Indigenous Art." Decolonization: Indigeneity, Education \& Society 3 (I). jps.library. utoronto.ca/index.php/des/article/view/21320

Marx, Karl. I887. Capital. Translated by Samuel Moore and Edward Aveling. Moscow: Progress Publishers. marxists.org/archive/marx/works/download/pdf/Capital-Volume-I.pdf

Mathews, Brian. 20I4. "Librarian as Futurist: Changing the Way Libraries Think About the Future." Portal: Libraries and the Academy I4 (3): 453-62. doi.org/IO.I353/pla.20I4.00I9

Nicholson, Karen. 20I8. "On the Space/Time of Information Literacy, Higher Education, and the Global Knowledge Economy." Journal of Critical Library and Information Studies 2 (I). doi.org/IO.24242/jclis. v2ir.86

- - 2015. "The McDonaldization of Academic Libraries and the Values of Transformational Change." College \& Research Libraries 76 (3): 328-38. doi.org/I0.5860/crl.76.3.328

Noble, Safiya Umoja. 20I8. Algorithms of Oppression: How Search Engines Reinforce Racism. New York: New York University Press.

Noble, Safiya Umoja, and Sarah T. Roberts. 20I8. "Engine Failure: Safiya Umoja Noble and Sarah T. Roberts on the Problems of Platform Capitalism." Logic Magazine, 20I8. logicmag.io/justice/safiyaumoja-noble-and-sarah-t-roberts/

Pagotto, Sabina. 2019. "Introducing Omni: A New Academic Search Tool from I4 Ontario University Libraries." Ontario Council of University Libraries. ocul.on.ca/introducing-omni

Peters, Thomas A. 20II. "Left to Their Own Devices: The Future of Reference Services on Personal, Portable Information, Communication, and Entertainment Devices." Reference Librarian 52 (I/2): 88-97. doi.org/IO.IO80/02763877.2011.520110

Popowich, Sam. 2019. “The Power of Knowledge, Objectified': Immaterial Labor, Cognitive Capitalism, and Academic Librarianship." Library Trends 68 (2): I53-73. doi.org/IO.I353/lib.2019.0035

Reidsma, Matthew. 2019. Masked by Trust: Bias in Library Discovery. Sacramento, CA: Litwin Books.

—— . 2016. "Algorithmic Bias in Library Discovery Systems." Matthew Reidsma. doi.org/I0.528I/ ZENODO.47723

Reser, Anna, Leila McNeill, and Rebecca Ortenberg. 20I8. "Scientific Racism and the Myth of Raw Data." Lady Science. Accessed September I2, 2020. ladyscience.com/podcast/episode-II-the-myth-ofraw-data-and-scientific-racism-2lphp 
Rhodes, Erin, Leah Richardson, and Rachel Trent. 20I8. "Invisible Labor." Slides presented at the RBMS 20I8, New Orleans, June. docs.google.com/presentation/d/IWVP5OjtEf7lObLo9TOP_8aWHIw757BWNu2IvZ8Irqo/

Russell, Andrew, and Lee Vinsel. 2016. "Hail the Maintainers." Aeon. Last modified April 7, 20I6. aeon. co/essays/innovation-is-overvalued-maintenance-often-matters-more

Santamaria, Michele R. 2020. "Concealing White Supremacy through Fantasies of the Library: Economies of Affect at Work." Library Trends 68 (3): 43I-49. doi.org/IO.I353/lib.2020.0000

Schmidt, Jane. 2018. "Innovate This! Bullshit in Academic Libaries." Presented at the CAPAL 2018, Regina, SK. digital.library.ryerson.ca/islandora/object/RULA\%3A7II3

Schreiber, Trine. 2019. "Documents as Social Actors: A Study of Digital Tutorials Using Actor-NetworkTheory and the Concept of Documentary Practices." Information Research 24 (4). informationr.net/ ir/24-4/colis/colisi932.html

Seale, Maura, and Rafia Mirza. 2020. "Who Killed the World? White Masculinity and the Technocratic Library of the Future." M. Sacramento: OSF. osf.io/p5vxm/

- - 2019. "Empty Presence: Library Labor, Prestige, and the MLS." Library Trends 68 (2): 252-68. doi. org/I0.1353/lib.2019.0038

Selman, Brianne, and Joe Curnow. 20I9. “Winnipeg's Millennium Library Needs Solidarity, Not Security." Partnership: The Canadian Journal of Library and Information Practice and Research I4 (2). doi. org/IO.21083/partnership.vi4i2.542I

Settoducato, Leo. 20I9. "Intersubjectivity and Ghostly Library Labor." In the Library with the Lead Pipe. inthelibrarywiththeleadpipe.org/20I9/intersubjectivity-and-ghostly-library-labor/

Sierpe, Eino. 2019. "Confronting Librarianship and Its Function in the Structure of White Supremacy and the Ethno State." Journal of Radical Librarianship 5 (May): 84-IO2.

Star, Susan Leigh. 1995. Ecologies of Knowledge: Work and Politics in Science and Technology. SUNY Series in Science, Technology, and Society. Albany: State University of New York Press.

The Verge. 2019. “The 84 Biggest Flops, Fails, and Dead Dreams of the Decade in Tech." The Verge. December 20, 20I9. perma.cc/UJ2B-4BRR

Widdicombe, Richard P. 2003. "Evolution of a Revolution: The Movement to 24/7 Web-Based Libraries." Science \& Technology Libraries 24 (I-2): I87-94. doi.org/IO.I300/JI22V24noI_I2

Xwi7xwa Library. 2020. "Research Guides: Indigenous Librarianship : Home." Accessed September Io, 2020. guides.library.ubc.ca/Indiglibrarianship/home 